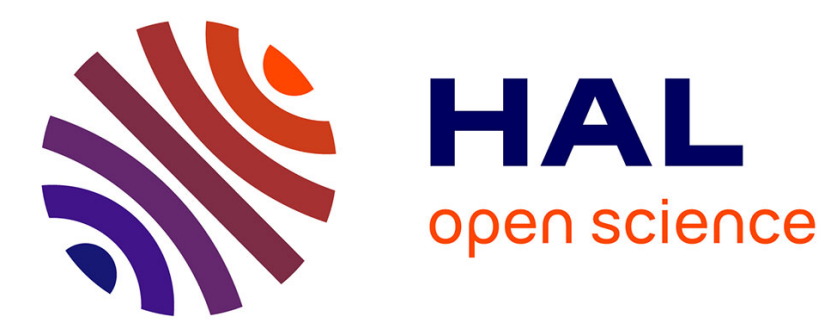

\title{
Artefacts in electrochemical impedance measurement in electrolytic solutions due to the reference electrode
}

\author{
Anh Tuan Tran, François Huet, Kieu Ngo, Philippe Rousseau
}

\section{To cite this version:}

Anh Tuan Tran, François Huet, Kieu Ngo, Philippe Rousseau. Artefacts in electrochemical impedance measurement in electrolytic solutions due to the reference electrode. Electrochimica Acta, 2011, 56 (23), pp.8034-8039. 10.1016/j.electacta.2010.12.088 . hal-00822828

\section{HAL Id: hal-00822828 \\ https://hal.sorbonne-universite.fr/hal-00822828}

Submitted on 14 Apr 2015

HAL is a multi-disciplinary open access archive for the deposit and dissemination of scientific research documents, whether they are published or not. The documents may come from teaching and research institutions in France or abroad, or from public or private research centers.
L'archive ouverte pluridisciplinaire HAL, est destinée au dépôt et à la diffusion de documents scientifiques de niveau recherche, publiés ou non, émanant des établissements d'enseignement et de recherche français ou étrangers, des laboratoires publics ou privés. 


\title{
Artefacts in electrochemical impedance measurement in electrolytic solutions due to the reference electrode
}

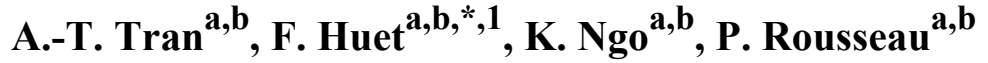 \\ ${ }^{a}$ CNRS, UPR15, Laboratoire Interfaces et Systèmes Electrochimiques, F-75005 Paris, France \\ ${ }^{b}$ UPMC Univ Paris 06, UPR15, LISE, 4 place Jussieu, F-75005 Paris, France
}

\begin{abstract}
Electrochemical impedance measurements performed on gas-evolving electrodes in highconductivity solutions have shown artefacts at high frequency (HF) when using a commercial reference electrode (RE) due to its relatively high impedance. A "trick" consisting in coupling a platinum wire in series with a capacitor of $0.1 \mu \mathrm{F}$ to the standard $\mathrm{RE}$, hence making a dual $\mathrm{RE}$, has been used for a long time without a clear understanding of how it works. This paper investigates HF EIS measurements in high-conductivity solutions from experiments in $1 \mathrm{M} \mathrm{H}_{2} \mathrm{SO}_{4}$ solutions and simulations based on the equivalent circuit of the cell and of the electrode potential measurement device. In particular, the value of the capacitor and the position of the platinum wire are considered. Curiously, while the HF artefact is removed by the dual RE, a spurious loop may appear at low frequency depending on the position of the platinum wire. This is explained from simulations based on the equivalent circuit of the cell.
\end{abstract}

Keywords: EIS; reference electrode; platinum wire; capacitor; artefact

\footnotetext{
*Corresponding author. Tel.: +33-1-44274148; fax: 33-1-44274074

E-mail address: francois.huet@upmc.fr(F. Huet)

${ }^{1}$ ISE Member
} 


\section{Introduction}

Artefacts due to the high impedance of standard reference electrodes (RE), used for controlling or measuring the working electrode (WE) potential in a 3-electrode electrochemical cell, have been observed for a long time, especially when using a Luggin capillary. They result in excessively long potential rise times in transient pulse experiments [1-3] while distortions appear in electrochemical impedance measurements [4-13]. The main effect is the deviation of the highfrequency limit of the impedance from the electrolyte resistance but the faradaic frequency range $(10 \mathrm{~Hz}-100 \mathrm{~Hz})$ [7], and even the low-frequency range [12], may also be affected. Most artefacts have been encountered in highly-resistive aqueous or non-aqueous media, and in solid-electrolyte cells. In 1968, Herrmann, Perrault, and Pilla [1] proposed a trick, which was largely used thereafter $[2-4,6,9-11,13,14]$ without a clear understanding of how it works. It consists in coupling a platinum wire in series with a capacitor of $0.1 \mu \mathrm{F}$ to the standard RE, hence making a dual RE operating properly: the dc component of the WE potential is controlled or measured by the standard RE and the impedance of the RE is short-circuited by the low impedance of the Pt wire at high frequency, which in addition results in the attenuation of mains interference [1,15]. Pt wires are sometimes used without connection with the RE through a capacitor $[15,16]$ but they do not maintain a constant dc potential over long periods of time, therefore, their use must be restricted to shortduration measurements such as fast pulse experiments.

An electrical equivalent circuit of the electrochemical cell has been introduced by some authors [7] to explain the difference in the impedance measured either with a standard $\mathrm{RE}$ or a $\mathrm{Pt}$ wire in low-conductivity media. It allows the role of the electrolyte conductivity and of the impedance of the standard RE on the artefacts observed in the WE impedance diagram at high frequency to be described. In 1996, a series of papers have been published in the rising field of solid-state electrochemistry to explain the artefacts in impedance measurements in three-electrode cells from the equivalent circuit of both the electrochemical cell and the potential measurement device $[9,10]$. Unfortunately, these papers do not seem to be known in the field of liquid-electrolyte 
electrochemistry. It is shown that the impedance of the RE and the input impedance of the voltage amplifier constitute a voltage divider that is at the origin of the spurious capacitive arcs and inductive loops measured at high frequency in low-conductivity electrolytes.

This paper is aimed at showing that artefacts in impedance measurements may be encountered in electrolytic solutions, even those of high conductivity. The role of the platinum wire in the dual RE will be revisited through impedance simulations based on the electrical circuit of the experimental arrangement and on measurements of the impedance of both the RE and Pt wire. Very few papers consider the influence on the measured impedance of the position of the Pt wire in the cell. It will be shown that this position is of primary importance in the whole frequency range analyzed. The influence of the coupling capacitor will also be examined. In practice, a customary value of $0.1 \mu \mathrm{F}$ is used in most experimental works but values up to $1 \mathrm{mF}$ are sometimes employed [11].

\section{Theoretical treatment}

Fig. 1 shows the electrical equivalent circuit of an electrochemical cell with a Pt wire connected to a standard RE through a capacitor. No connections are shown to a potentiostat or a galvanostat since this equivalent circuit may be used appropriately when the cell is under potential control or under current control. $Z(f), Z_{\mathrm{p}}(f)$, and $Z_{\mathrm{RE}}(f)$ are the impedances at frequency $f$ of the WE, Pt wire, and RE, respectively. $R_{\mathrm{e}}=r_{1}+r_{2}$ represents the electrolyte resistance between the WE and the standard RE while $r_{2}$ is the electrolyte resistance between the WE and the tip of the Pt wire. Finally, $C_{\mathrm{p}}$ stands for the capacitance of the capacitor in series with the Pt wire.

The current, $i$, flowing through the cell is measured from the voltage drop across a precision resistor, $R_{\mathrm{m}}$, connected to the CE. The output signal, $s_{\mathrm{I}}$, of the differential amplifier of gain $G_{\mathrm{I}}$ is then:

$$
s_{\mathrm{I}}=R_{\mathrm{m}} G_{\mathrm{I}} i
$$


The potential difference between the RE and the WE is measured with the help of a differential amplifier of gain $G_{\mathrm{V}}$. $Z_{\text {in }}(f)$ represents both the input impedance of the amplifier and the impedance of the cable connected to the RE. Therefore, $Z_{\text {in }}$ is the same for experiments performed under current or potential control as long as the same voltage amplifier is used in the potentiostat and in the galvanostat. More precisely, $Z_{\text {in }}$ can be modelled with a resistance $R_{\text {in }}$ in parallel with a capacitance $C_{\text {in }}$. It is now common practice to use amplifiers with $R_{\text {in }}$ values as high as $10^{12} \Omega$ so that the contribution of $R_{\text {in }}$ in the impedance $Z_{\text {in }}$ is negligible and will be disregarded in this paper. As a consequence, $Z_{\text {in }}$ may be written:

$$
Z_{\text {in }}=\frac{1}{j \omega C_{\text {in }}}
$$

where $\omega$ is the pulsation ( $\omega=2 \pi f)$ and $C_{\text {in }}$ is the sum of the input capacitance of the amplifier and of the RE cable capacitance, which has to be taken into account especially when a grounded coaxial cable is used to minimize interference of the mains.

The output signal of the voltage amplifier, $s_{\mathrm{V}}$, may be expressed as:

$$
s_{\mathrm{V}}=G_{\mathrm{V}}\left(r_{1}\left(i-i_{1}\right)+\left(r_{2}+Z\right)\left(i-i_{2}\right)-Z_{\mathrm{RE}} i_{1}\right)
$$

where $i_{1}$ and $i_{2}$ are the currents flowing across the RE and the input impedance of the voltage amplifier, respectively. The impedance, $Z_{\text {meas }}(f)$, measured from $s_{\mathrm{I}}$ and $s_{\mathrm{V}}$ can be calculated from the following two equations obtained by writing Ohm's law in two branches of the equivalent circuit (Fig. 1):

$$
\begin{aligned}
& r_{1}\left(i-i_{1}\right)+\left(r_{2}+Z\right)\left(i-i_{2}\right)=Z_{\mathrm{RE}} i_{1}+Z_{i n} i_{2} \\
& Z_{\mathrm{RE}} i_{1}+\left(\frac{1}{j \omega C_{\mathrm{p}}}+Z_{\mathrm{p}}\right)\left(i_{1}-i_{2}\right)=r_{1}\left(i-i_{1}\right)
\end{aligned}
$$

It should be noted that all current and voltage quantities in Eqs. (1-5) are frequency dependent. In other words, they are the Fourier transforms of the corresponding quantities in the time domain.

In standard (no Pt wire) and ideal $\left(Z_{\text {in }}=\infty\right)$ conditions, which give $i_{1}=i_{2}=0$, the out put of the voltage amplifier is: 


$$
s_{\mathrm{V}}=G_{\mathrm{V}}\left(r_{1}+r_{2}+Z\right) i=G_{\mathrm{V}}\left(R_{\mathrm{e}}+Z\right) i
$$

so that: $\quad \frac{s_{\mathrm{V}}}{s_{\mathrm{I}}}=\frac{G_{\mathrm{V}}}{R_{\mathrm{m}} G_{\mathrm{I}}}\left(R_{\mathrm{e}}+Z\right)$

and the measured impedance is: $\quad Z_{\text {meas }}=\frac{R_{\mathrm{m}} G_{\mathrm{I}}}{G_{\mathrm{V}}} \frac{s_{\mathrm{V}}}{s_{\mathrm{I}}}=R_{\mathrm{e}}+Z$

In this study (Pt wire and finite $Z_{\text {in }}$ ), Eqs. (4-5) allow the currents $i_{1}$ and $i_{2}$ to be calculated as a function of $I$, and, from Eq. (1), Eq. (3), and Eq. (8), the measured impedance is derived:

$$
Z_{\text {meas }}=\frac{R_{\mathrm{m}} G_{\mathrm{I}}}{G_{\mathrm{V}}} \frac{s_{\mathrm{V}}}{s_{\mathrm{I}}}=\frac{\left(r_{1}+r_{2}+Z\right)+j \omega C_{\mathrm{p}}\left\lfloor\left(r_{1}+r_{2}+Z\right)\left(r_{1}+Z_{\mathrm{RE}}+Z_{\mathrm{p}}\right)-r_{1}\left(r_{1}+Z_{\mathrm{RE}}\right)\right\rfloor}{\left(1+\frac{r_{2}+Z}{Z_{\text {in }}}\right)\left(1+j \omega C_{\mathrm{p}}\left(r_{1}+Z_{\mathrm{RE}}+Z_{\mathrm{p}}\right)\right)+\frac{r_{1}+Z_{\mathrm{RE}}}{Z_{\text {in }}}\left(1+j \omega C_{\mathrm{p}} Z_{\mathrm{p}}\right)}
$$

The current flowing through the cell may also be measured with a current-to-voltage converter connected to the WE. In that case, the output of the converter can be written as:

$$
s_{\mathrm{I}}=G\left(i-i_{2}\right)
$$

where $G$ is the gain of the converter in V/A. From the expressions of $i_{1}$ and $i_{2}$, Eq. (3), Eq. (8), and Eq. (10) give the measured impedance.

$$
Z_{\text {meas }}=\frac{G}{G_{\mathrm{V}}} \frac{s_{\mathrm{V}}}{s_{\mathrm{I}}}=\frac{\left(r_{1}+r_{2}+Z\right)+j \omega C_{\mathrm{p}}\left\lfloor\left(r_{1}+r_{2}+Z\right)\left(r_{1}+Z_{\mathrm{RE}}+Z_{\mathrm{p}}\right)-r_{1}\left(r_{1}+Z_{\mathrm{RE}}\right)\right\rfloor}{1+j \omega C_{\mathrm{p}}\left(r_{1}+Z_{\mathrm{RE}}+Z_{\mathrm{p}}\right)+\frac{Z_{\mathrm{RE}}}{Z_{\text {in }}}\left(1+j \omega C_{\mathrm{p}} Z_{\mathrm{p}}\right)}
$$

\section{Experimental}

All experiments in this work were carried out at room temperature in a large horizontal cylindrical glass cell with a single compartment of $21 \mathrm{~cm}$ in length and $10 \mathrm{~cm}$ in diameter opened to air on the top. On one side, the cell was closed with a flat glass disk for visual observations of the WE. The distance between the WE holder and the standard RE was about $8 \mathrm{~cm}$. The electrolyte was a $1 \mathrm{M} \mathrm{H}_{2} \mathrm{SO}_{4}$ solution. A high-purity platinum rod of $0.5 \mathrm{~cm}$ in diameter was used as WE. Its lateral surface was insulated with an epoxy resin so that the active surface $\left(0.2 \mathrm{~cm}^{2}\right)$ exposed to the electrolyte was its cross section. Before use, the WE was ground successively to $600,1,200,2,400$ 
and 4,000-grit emery papers and polished with diamond paste down to $1 \mu \mathrm{m}$ particle size. Thereafter, the WE was polished in a super finishing suspension (POM $8^{\odot}$ from ESCIL, France) and finally rinsed with deionised water in an ultrasonic bath for $15 \mathrm{~min}$ to remove diamond grains. The WE was placed close to the flat side of the cell, facing upwards to facilitate bubble release. The CE was a large platinum grid placed at the opposite side of the cell. The standard RE was a onecompartment saturated sulphate electrode (SSE) without Luggin capillary connected to the voltage amplifier by a grounded coaxial cable.

The impedance measurements were carried out during the investigation of hydrogen evolution under galvanostatic control at current densities of $-25 \mathrm{~mA} \mathrm{~cm}{ }^{-2}$ and $-100 \mathrm{~mA} \mathrm{~cm}{ }^{-2}$, with white noise or sine wave as excitation signals. The Pt wire of $0.1 \mathrm{~cm}$ in diameter connected to the SSE through a capacitor was inserted in a crosslinked polyolefin heat shrinkable tube to insulate its lateral surface, except on a $0.05 \mathrm{~cm}$ length at the tip, to sense the potential locally. For measuring the impedances of the SSE and the Pt wire, the WE was replaced by a similar SSE and the Pt wire, respectively. In that case, the applied current was set to zero since in operating conditions, no current can flow in a RE because of the high impedance of the voltage amplifier connected to the RE.

\section{Results and Discussion}

Fig.2 shows the Nyquist impedance diagrams measured during hydrogen evolution in the $1 \mathrm{M} \mathrm{H}_{2} \mathrm{SO}_{4}$ solution under galvanostatic control with the standard SSE (curve A) and a dual RE (curve B) at a current density of $-25 \mathrm{~mA} \mathrm{~cm}^{-2}$. A white noise was used as excitation signal and the frequency range analyzed was $[500 \mathrm{~Hz}, 37 \mathrm{kHz}$. The amplitude of the current excitation was chosen so that the root-mean-square value of the amplitude of the potential response did not exceed $10 \mathrm{mV}$, which was systematically checked on the potential time records acquired. This ensured that the perturbation current amplitude provided a linear potential response at all frequencies. The highfrequency (HF) limit of the impedance gives the electrolyte resistance, $R_{\mathrm{e}}$, which was close to $4 \Omega$ 
in the present conditions. This value is slightly higher than the theoretical value of $2.5 \Omega$ given by Newman's expression [17], $R_{\mathrm{e}}=\rho / 2 d$ (solution resistivity $\rho=2.5 \Omega \mathrm{cm}$, diameter of the WE $d=0.5$ $\mathrm{cm}$ ), because of the non-ideal conditions (CE not at infinity) and the presence of hydrogen bubbles attached to the WE. The HF limit of curve A tends to a value of $2 \Omega$, indicating that the HF part of the diagram was not correctly measured with the SSE. In contrast, the presence of the dual $\mathrm{RE}\left(C_{\mathrm{p}}=\right.$ $0.47 \mu \mathrm{F}$ ) with the Pt wire close to the SSE (curve B) ensured valid measurements. Other values of $C_{\mathrm{p}}(47 \mathrm{nF}$ and $3,3 \mu \mathrm{F})$ gave the same impedance curve.

From Eq. (2) and Eq. (9) with $C_{\mathrm{p}}=0$ and $r_{1}=0$, and considering that the impedance of the $\mathrm{RE}$ can be approximated by a resistance, $R_{\mathrm{RE}}$, much larger than the WE impedance (see below), the impedance of the WE measured without the Pt wire is given by:

$$
Z_{\text {meas }}(\omega)=\frac{R_{\mathrm{e}}+Z}{1+j \omega C_{\mathrm{in}}\left(R_{\mathrm{e}}+Z+Z_{\mathrm{RE}}\right)} \approx \frac{R_{\mathrm{e}}+Z}{1+j \omega C_{\mathrm{in}} R_{\mathrm{RE}}}
$$

From the imaginary part of the ratio of $R_{\mathrm{e}}+Z$ (curve B) to $Z_{\text {meas }}$ (curve A), the time constant $R_{\mathrm{RE}} C_{\text {in }}$ can be evaluated. Values of $1.7 \mu \mathrm{s}$ and $1.2 \mu \mathrm{s}$ at $10 \mathrm{kHz}$ and $30 \mathrm{kHz}$, respectively, have been found, which shows that $Z_{\mathrm{RE}}$ was not exactly a pure resistance (see below). Nevertheless, to determine a rough estimate of $R_{\mathrm{RE}}$, a specific measurement of $C_{\text {in }}$ was performed. The electrochemical cell was replaced by a resistor of $R=150 \mathrm{k} \Omega$, the ground shielded cable still being connected to the voltage amplifier. The Bode plot of the impedance modulus of the resistor measured potentiostatically shows a plateau at low frequency followed by a $1 /$ f decrease above a cut-off frequency $1 /\left(2 \pi R C_{\text {in }}\right)$ of $4.5 \mathrm{kHz}$, from which the value $C_{\mathrm{in}}=240 \mathrm{pF}$ was found. Replacing the shielded cable by a nongrounded cable, a value of $40 \mathrm{pF}$ was found for $C_{\mathrm{in}}$, indicating that the contribution of the ground shielded cable to $C_{\text {in }}$ was about $200 \mathrm{pF}$, the rest being due to the stray capacitances of the voltage amplifier and circuitry. From the $R_{\mathrm{RE}} C_{\mathrm{in}}$ value of $1.2 \mu \mathrm{s}$ at $30 \mathrm{kHz}$, the resistance of the RE can be roughly estimated to $R_{\mathrm{RE}}=5 \mathrm{k} \Omega$.

The impedance of the WE, $Z(f)$, was modelled by a charge-transfer resistance, $R_{\mathrm{t} 1}$, in parallel with a constant-phase element (CPE) of parameters $Q_{1}$ and $\alpha_{1}$. A good agreement was obtained 
between the measured and fitted impedance spectra (Curves B and C in Fig. 2) with the following parameters: $R_{\mathrm{e}}=3.9 \Omega, R_{\mathrm{t} 1}=23.8 \Omega, \alpha_{1}=0.88$, and $Q_{1}=6.3 \mu \mathrm{F} \mathrm{s}{ }^{\alpha_{1}-1}$. With these 4 parameters in the expression of $Z+R_{\mathrm{e}}$, Eq. (12) gives the impedance spectrum (curve D) that would be measured with $R_{\mathrm{RE}}=5 \mathrm{k} \Omega$ and $C_{\mathrm{in}}=240 \mathrm{pF}$. The good agreement between Curves $\mathrm{A}$ and $\mathrm{D}$ at frequencies lower than $25 \mathrm{kHz}$ is experimental evidence that the artefact in the impedance measurement at high frequency was due to the combined effect of the SSE and the capacitance $C_{\text {in }}$. The slight discrepancy observed between $25 \mathrm{kHz}$ and $37 \mathrm{kHz}$ comes from the fact that the impedance of the SSE was not constant at these frequencies, as assumed in Eq. (12).

The Bode diagram (modulus and phase) of the impedance of a brand new SSE, measured at a zero current using a dual RE and a sine wave as excitation signal, is shown in Fig. 3. The modulus of the impedance is constant in a wide frequency range $[0.1 \mathrm{~Hz}-10 \mathrm{kHz}]$, which justifies the approximation used in Eq. (12). The resistance $R_{\mathrm{RE}}=5 \mathrm{k} \Omega$ of the RE used above was larger that the resistance of $2.1 \mathrm{k} \Omega$ of the brand new SSE, indicating that the porous frit at the sensing junction of the RE was partially blocked or damaged although the WE potential given by the RE was correct. In the following, the RE impedance is modelled by a simple pure resistance $R_{\mathrm{RE}}=2.1 \mathrm{k} \Omega$ for simplification in the simulations.

In the same way, the impedance of the $\mathrm{Pt}$ wire was measured in the $1 \mathrm{M} \mathrm{H}_{2} \mathrm{SO}_{4}$ solution at a zero current using a dual RE (Fig. 4). It was modelled by three resistors in series, two of them in parallel with a CPE, hence giving the expression:

$$
Z_{\mathrm{p}}(\omega)=R_{1}+\frac{R_{2}}{1+R_{2} Q_{2}(j \omega)^{\alpha_{2}}}+\frac{R_{3}}{1+R_{3} Q_{3}(j \omega)^{\alpha_{3}}}
$$

Although this model was not physical, it was used in the following simulations since it gave the best fitting results (solid lines in Fig. 4), especially for the impedance modulus, which allows the contribution of the impedance of the Pt wire to be taken into account precisely in the simulations. The values of the parameters given in the figure caption have been used in all simulations, except $R_{1}$ that was fixed to 0 since the solution resistance was taken into account by $r_{1}$ and $r_{2}$. 
A new set of experiments was carried out at a current density of $-100 \mathrm{~mA} \mathrm{~cm}{ }^{-2}$ with the brand new RE to study the influence of the position of the Pt wire on the measured impedance of the WE. Simulations were also performed to investigate the effect of the parameters $C_{\mathrm{in}}, R_{\mathrm{RE}}$, and $C_{\mathrm{p}}$ on $Z_{\text {meas. }}$ The Pt wire was attached to the SSE, its tip being at a distance slightly above $(0.2 \mathrm{~cm})$ the sensing junction of the RE (position A, see below). Fig. 5 shows a good agreement between the measured EIS diagram (curve A, open squares) and the diagram fitted with 5 variable parameters $R_{\mathrm{e}}, R_{\mathrm{t} 1}, \alpha_{1}, Q_{1}, r_{1}$, and fixed values $R_{\mathrm{RE}}=2.1 \mathrm{k} \Omega$ and $C_{\mathrm{in}}=240 \mathrm{pF}$ (curve B, solid line). Another fitting was performed with only 4 variable parameters $R_{\mathrm{e}}, R_{\mathrm{t} 1}, \alpha_{1}, Q_{1}$ and $r_{1}=0$ but the khi value was higher and the values of the 4 parameters obtained were in less agreement with those found for the other positions of the Pt wire (see Table 1). Curve C, simulated with the same parameters except $r_{1}=0$, shows the EIS diagram that should have been measured if the tip of the Pt wire had been closer to the sensing junction of the SSE. Curve D shows the significant artefact at HF induced by the impedance of the SSE in the absence of Pt wire $\left(C_{\mathrm{p}}=0, r_{1}=0\right)$.

The stray capacitance $C_{\text {in }}$ due to the voltage amplifier and the RE cable has a major influence in the EIS measurement at HF. It was estimated to be equal to $240 \mathrm{pF}$ in this work. To better evaluate its role in the absence of Pt wire, the WE impedance was simulated with Eq. (11) for various values of $C_{\text {in }}$ and the same parameters as before for $Z, R_{\mathrm{e}}, Z_{\mathrm{p}}$, and $R_{\mathrm{RE}}$. Fig. 6 shows that even with a low value of $C_{\text {in }}=40 \mathrm{pF}$, corresponding to a non-grounded $\mathrm{RE}$ cable in this work, an additional and spurious loop appears at HF for the RE used of impedance $2.1 \mathrm{k} \Omega$ (curve $\mathrm{B}$ ). In other words, without the Pt wire, the impedance is correctly measured for frequencies lower than about $10 \mathrm{kHz}$ when $C_{\text {in }}=40 \mathrm{pF}$. As long as the capacitance $C_{\text {in }}$ increases, the frequency limit decreases (curves $\mathrm{C}$ and $\mathrm{D}$ ). These results confirm that the use of a Pt wire is highly recommended to obtain correct impedance measurements at HF. Obviously, for a given experimental arrangement, that is a given value of $C_{\mathrm{in}}$, the $\mathrm{HF}$ artefact becomes more important for increasing values of the RE resistance, as shown in Fig. 7. 
In the literature, several values of capacitance $C_{\mathrm{p}}$ have been used for the capacitor connected in series with the Pt wire, the most commonly used being $0.1 \mu \mathrm{F}$. Simulation results obtained with different values of $C_{\mathrm{p}}$ are shown in Fig. 8 for a fixed capacitance $C_{\text {in }}=240 \mathrm{pF}$ and the same parameters as before for $Z, R_{\mathrm{e}}, Z_{\mathrm{p}}$, and $R_{\mathrm{RE}}$. For $C_{\mathrm{p}}=1 \mathrm{nF}$ (curve B), the HF limit of the impedance no longer tends to 0 as in the absence of Pt wire (curve A). A slight effect of the RE impedance is still observed for $C_{\mathrm{p}}=10 \mathrm{nF}$ and all EIS curves converge for $C_{\mathrm{p}}$ values higher than $47 \mathrm{pF}$. The commonly used value of $C_{\mathrm{p}}=0.1 \mu \mathrm{F}$ is then well adapted in this study but it should be noted that the result depends on the magnitude of the impedances of the WE, RE, and Pt wire, and, therefore, should be taken with care in other studies.

So far, all results in this work were obtained with a Pt wire, the tip of which was positioned at a small distance of the sensing junction of the RE to monitor the potential at the same point in the electrolyte. The solution resistance between these two electrodes was modelled by a small resistance $r_{1}$. It is now shown that the position of the $\mathrm{Pt}$ wire relative to the RE and to the WE plays a primordial role in the EIS measurements. Fig. 9a shows the measured impedance diagrams for 5 positions of the Pt wire given in the inset of the figure: (A) parallel with the RE, (B) in front of the RE, (C) at $2 \mathrm{~cm}$ from the RE, (D) close to the WE, and (E) behind the RE. A capacitance $C_{\mathrm{p}}=$ $0.47 \mu \mathrm{F}$, far higher than the value of $47 \mathrm{nF}$ identified above for the studied system, was used. It can be seen that different EIS diagrams can be measured depending on the position of the Pt wire. Indeed, the impedance measured at HF is that given by the Pt wire that short-circuits the SSE. When the Pt wire is moved away from the RE (curves B, C), the HF part of the EIS diagram is distorted because the HF limit of the impedance is $r_{2}=R_{\mathrm{e}}-r_{1}$ (Fig. 1) and $r_{1}$ increases. On the other hand, when the Pt wire is positioned behind the RE (curve E), it is partially hidden by the RE and no longer plays its role at HF. In that case, the EIS curve is very similar to that obtained in the absence of Pt wire (curve D in Fig. 5). Finally, when the Pt wire is placed near the working electrode (curve D), an additional capacitive loop curiously appears at low frequency because of a complex effect of the capacitor $C_{\mathrm{p}}$ in series with the Pt wire. This low-frequency capacitive loop 
may also be measured at a lower current density $\left(-25 \mathrm{~mA} \mathrm{~cm}^{-2}\right)$, as shown in Fig. 9 b. Obviously, the charge-transfer resistance being 4 times higher, the loop is not predominant but careful examination shows that its size is still the same.

Fig. 10 shows the diagrams fitted with 5 variable parameters $R_{\mathrm{e}}, R_{\mathrm{t} 1}, \alpha_{1}, Q_{1}, r_{1}$ for positions $\mathrm{A}, \mathrm{B}, \mathrm{C}$, and D of the Pt wire. $R_{\mathrm{RE}}=2.1 \mathrm{k} \Omega, C_{\mathrm{in}}=240 \mathrm{pF}$, and the same values as before for $Z_{\mathrm{p}}$ have been used. The EIS diagram with the Pt wire positioned behind the RE could not be fitted with the equivalent circuit used. The values of the parameters of the WE impedance obtained in the fitting procedure are given in Table 1. As expected, these values are very similar for all positions of the $\mathrm{Pt}$ wire, except when $r_{1}$ is fixed to 0 for position A, as discussed above. Excellent agreement may be observed between the fitted and experimental EIS Nyquist diagrams, which confirms that the equivalent circuit in Fig. 1 is well adapted for modelling the impedance of the WE when a dual RE is used.

\section{Conclusions}

Artefacts in EIS measurements at high frequency have been shown even for highconductivity solutions. They are due to the high impedance of the RE and to the stray capacitance of the cable connected to the voltage amplifier and to the input capacitance of this amplifier. The solution of the dual RE with a Pt wire in series with a capacitor connected to the RE, which has long been known, is explained in this paper thanks to EIS measurements and simulations based on the equivalent circuit of the cell and voltage amplifier.

The use of a dual RE is recommended at high frequency, in practice especially when information is involved in the EIS diagram above $10 \mathrm{kHz}$. The capacitance $C_{\mathrm{p}}$ of the capacitor in series with the Pt wire has to be carefully chosen. A value of $0.1 \mu \mathrm{F}$ is commonly used but this work shows that the adequate value depends on the impedance of the RE and on the parasite capacitance $C_{\text {in }}$ of the RE cable and measuring device. Simulations have shown that a capacitance 
of at least $47 \mathrm{nF}$ had to be used to obtain accurate EIS measurements up to $1 \mathrm{MHz}$ for the electrochemical system investigated.

This work also shows the strong influence of the position of the Pt wire relative to the RE and to the WE. The wire should be insulated on its lateral surface and the tip in contact with the electrolyte should be placed as close as possible to the sensing junction of the RE, both wire and RE being at the same distance of the WE (position A in Fig. 9a). 


\section{References}

[1] C.C. Herrmann, G.G. Perrault, A.A. Pilla, Anal. Chem. 40 (1968) 1173.

[2] W. Botter Jr., D.M. Soares, O. Teschke, J. Electroanal. Chem. 267 (1989) 279.

[3] S.W. Watson, B.W. Madsen, Corrosion 48 (1992) 727.

[4] H. Göhr, M. Mirnik, C.A. Schiller, J. Electroanal. Chem. 180 (1984) 273.

[5] J.P. De Souza, O.R. Mattos, L. Sathler, H. Takenouti, Corros. Sci. 27 (1987) 1351.

[6] F. Mansfeld, S. Lin, Y.C. Chen, H. Shih, J. Electrochem. Soc. 135 (1988) 906.

[7] S. Chechirlian, P. Eichner, M. Keddam, H. Takenouti, H. Mazille, Electrochim. Acta 35 (1990) 1125.

[8] M.C. Wiles, D.J. Schiffrin, T.J. VanderNoot, A.F. Silva, J. Electroanal. Chem. 278 (1990) 151.

[9] G. Hsieh, S.J. Ford, T.O. Mason, L.R. Pederson, Solid State Ionics 91 (1996) 191.

[10] G. Hsieh, T.O. Mason, L.R. Pederson, Solid State Ionics 91 (1996) 203.

[11] O. Poupard, A. Aït-Mokhtar, P. Dumargue, J. Mater. Sci. 38 (2003) 2845.

[12] G. Fafilek, Solid State Ionics 176 (2005) 2023.

[13] V. Horvat-Radošević, K. Kvastek, Electrochim. Acta 52 (2007) 5377.

[14] F. Mansfeld, M.W. Kendig, S. Tsai, Corrosion 38 (1982) 570.

[15] S. Fletcher, M.D. Horne, J. Electroanal. Chem. 297 (1991) 297.

[16] P.J. Moran, Corrosion 42 (1986) 432.

[17] J. Newman, J. Electrochem. Soc. 113 (1966) 501. 


\section{Figure and Table Captions}

Fig. 1. Electrical equivalent circuit of the electrochemical cell including a Pt wire connected to the RE through a capacitor.

Fig. 2. EIS Nyquist diagrams of $\mathrm{H}_{2}$ evolution on a Pt disk WE in $1 \mathrm{M} \mathrm{H}_{2} \mathrm{SO}_{4}$ under current control $\left(-25 \mathrm{~mA} / \mathrm{cm}^{2}\right):(\mathrm{A})$ measured with a SSE, (B) measured with a dual $\mathrm{RE}\left(\mathrm{C}_{\mathrm{p}}=0.47 \mu \mathrm{F}\right),(\mathrm{C})$ fitted from curve B, (D) derived from curve C with Eq. 12.

Fig. 3. Bode diagram of the impedance of a brand new saturated sulphate RE.

Fig. 4. Bode diagram of the measured impedance of the Pt wire (• modulus, $*$ phase angle). The solid lines represent the curves fitted with Eq. (13): $R_{1}=5.18 \Omega, R_{2}=23.9 \mathrm{k} \Omega, \alpha_{2}=0.813$, $Q_{2}=1.14 \mu \mathrm{F} \mathrm{s}^{\alpha_{2}-1}, R_{3}=1.87 \mathrm{M} \Omega, \alpha_{3}=0.842, Q_{3}=1.89 \mu \mathrm{F} \mathrm{s}^{\alpha_{3}-1}$.

Fig. 5. EIS Nyquist diagrams of $\mathrm{H}_{2}$ evolution on a $\mathrm{Pt}$ disk electrode in $1 \mathrm{M} \mathrm{H}_{2} \mathrm{SO}_{4}$ under current control $\left(-100 \mathrm{~mA} / \mathrm{cm}^{2}\right)$ : (A) measured with a dual $\mathrm{RE}\left(C_{\mathrm{p}}=0.47 \mu \mathrm{F}\right)$, (B) fitted from Eq. (11) and $R_{\mathrm{e}}=3.69 \Omega, R_{\mathrm{t} 1}=1.87 \Omega, \alpha_{1}=0.969, Q_{1}=14.8 \mu \mathrm{F} \mathrm{s} \mathrm{s}^{\alpha_{1}-1}, r_{1}=0.19 \Omega$, (C) simulated with Eq. (11) with the same parameters except $r_{1}=0$, (D) simulated with Eq. (11) with the same parameters and no Pt wire $\left(C_{p}=0, r_{1}=0\right)$.

Fig. 6. Simulated EIS Nyquist diagrams for $\mathrm{H}_{2}$ evolution on a $\mathrm{Pt}$ disk electrode in $1 \mathrm{M} \mathrm{H}_{2} \mathrm{SO}_{4}$ under current control $\left(-100 \mathrm{~mA} / \mathrm{cm}^{2}\right)$ as a function of the capacitance $C_{\text {in }}$ in the absence of Pt wire $\left(C_{\mathrm{p}}=0\right)$ with the same parameters as in Fig. 5 except $r_{1}=0$ : (A) $\mathrm{C}_{\mathrm{in}}=0,(\mathrm{~B}) \mathrm{C}_{\mathrm{in}}=$ $40 \mathrm{pF},(\mathrm{C}) \mathrm{C}_{\mathrm{in}}=140 \mathrm{pF},(\mathrm{D}) \mathrm{C}_{\mathrm{in}}=240 \mathrm{pF}$.

Fig. 7. Simulated EIS Nyquist diagrams for $\mathrm{H}_{2}$ evolution on a $\mathrm{Pt}$ disk electrode in $1 \mathrm{M} \mathrm{H}_{2} \mathrm{SO}_{4}$ under current control $\left(-100 \mathrm{~mA} / \mathrm{cm}^{2}\right)$ as a function of the resistance of the RE in the absence of Pt wire $\left(C_{\mathrm{p}}=0\right)$ with the same parameters as in Fig. 5 except $r_{1}=0$ :
(A) $\mathrm{R}_{\mathrm{RE}}=100 \Omega$,
(B) $R_{R E}=2.1 \mathrm{k} \Omega$,
(C) $\mathrm{R}_{\mathrm{RE}}=5 \mathrm{k} \Omega$,
(D) $R_{R E}=15 \mathrm{k} \Omega$.

Fig. 8. Simulated EIS Nyquist diagrams for $\mathrm{H}_{2}$ evolution on a Pt disk electrode in $1 \mathrm{M} \mathrm{H}_{2} \mathrm{SO}_{4}$ under current control $\left(-100 \mathrm{~mA} / \mathrm{cm}^{2}\right)$ as a function of the capacitance $C_{p}$ with the same 
parameters as in Fig. 5 except $r_{1}=0$ : (A) $C_{p}=0$ (no Pt wire), (B) $C_{p}=1 \mathrm{nF}$, (C) $\mathrm{C}_{\mathrm{p}}=10 \mathrm{nF},(\mathrm{D}) \mathrm{C}_{\mathrm{p}} \geq 47 \mathrm{nF}$.

Fig. 9. EIS Nyquist diagrams measured during $\mathrm{H}_{2}$ evolution on a $\mathrm{Pt}$ disk WE in $1 \mathrm{M} \mathrm{H}_{2} \mathrm{SO}_{4}$ under current control with a dual $\operatorname{RE}\left(C_{\mathrm{p}}=0.47 \mu \mathrm{F}\right)$ as a function of the position of the Pt wire shown in the inset: Current density (a) $-100 \mathrm{~mA} / \mathrm{cm}^{2}$, (b) $-25 \mathrm{~mA} / \mathrm{cm}^{2}$.

Fig. 10. Fitting of the EIS Nyquist diagrams shown in Fig. 9a (parameters of the simulation given in Table 1).

Table 1 Parameters obtained in the fitting of the EIS diagrams shown in Fig. 9a. 


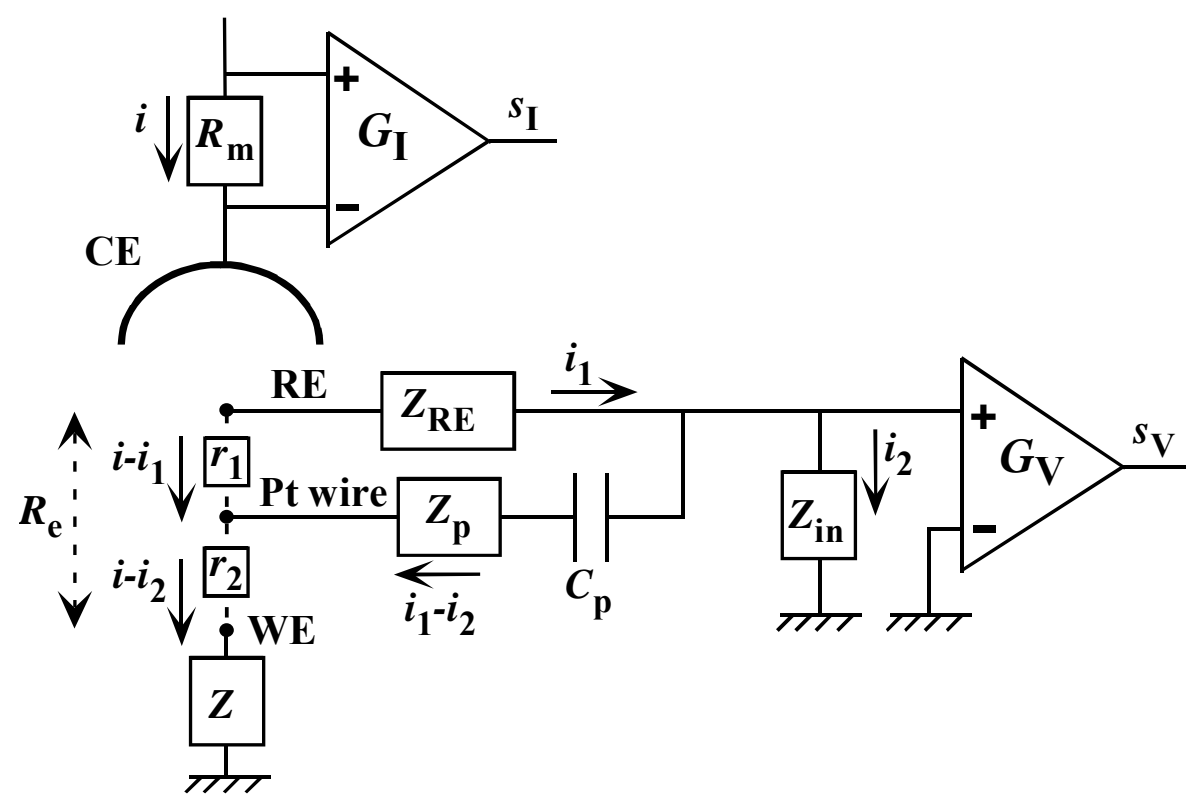

Fig. 1. Electrical equivalent circuit of the electrochemical cell including a Pt wire connected to the RE through a capacitor. 


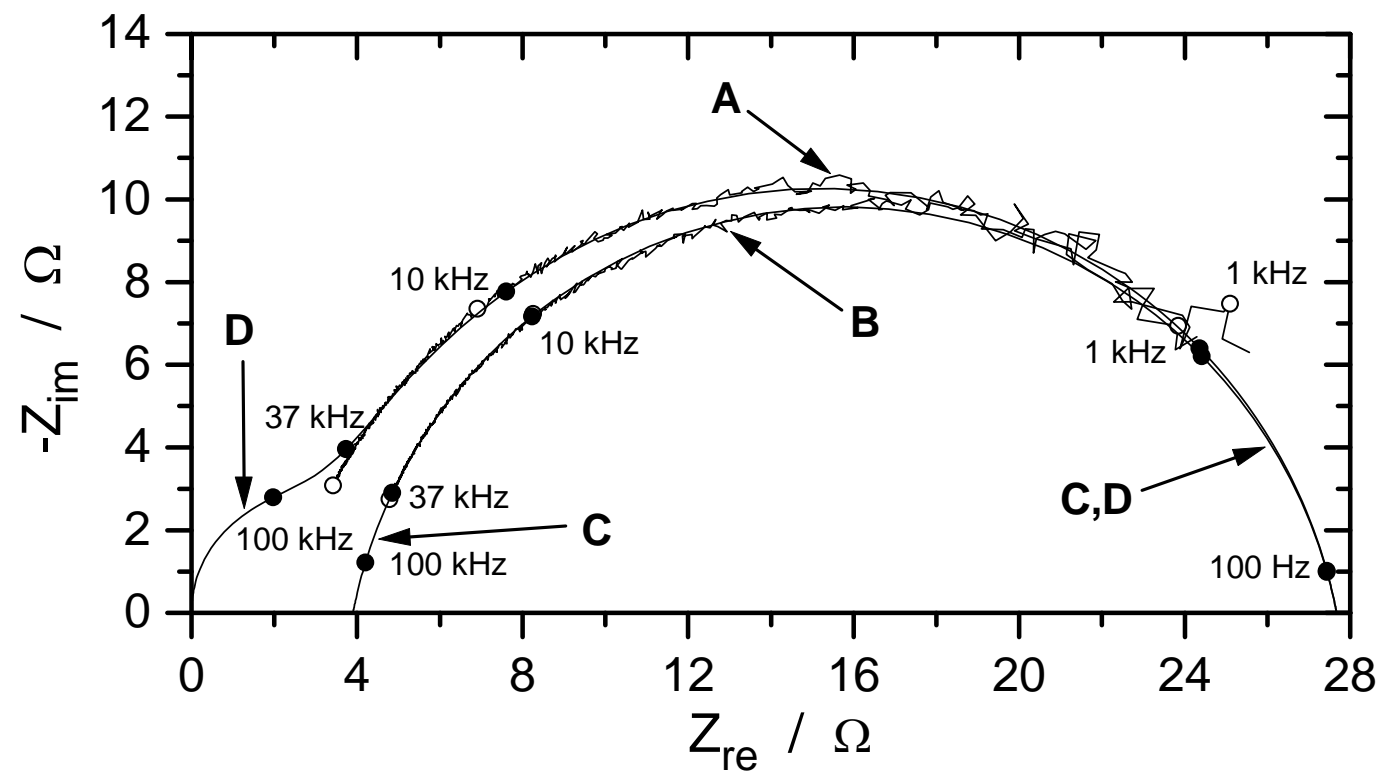

Fig. 2. EIS Nyquist diagrams of $\mathrm{H}_{2}$ evolution on a Pt disk WE in $1 \mathrm{M} \mathrm{H}_{2} \mathrm{SO}_{4}$ under current control $\left(-25 \mathrm{~mA} / \mathrm{cm}^{2}\right)$ : (A) measured with a SSE, (B) measured with a dual $\mathrm{RE}\left(\mathrm{C}_{\mathrm{p}}=0.47 \mu \mathrm{F}\right),(\mathrm{C})$ fitted from curve B, (D) derived from curve C with Eq. 12 . 


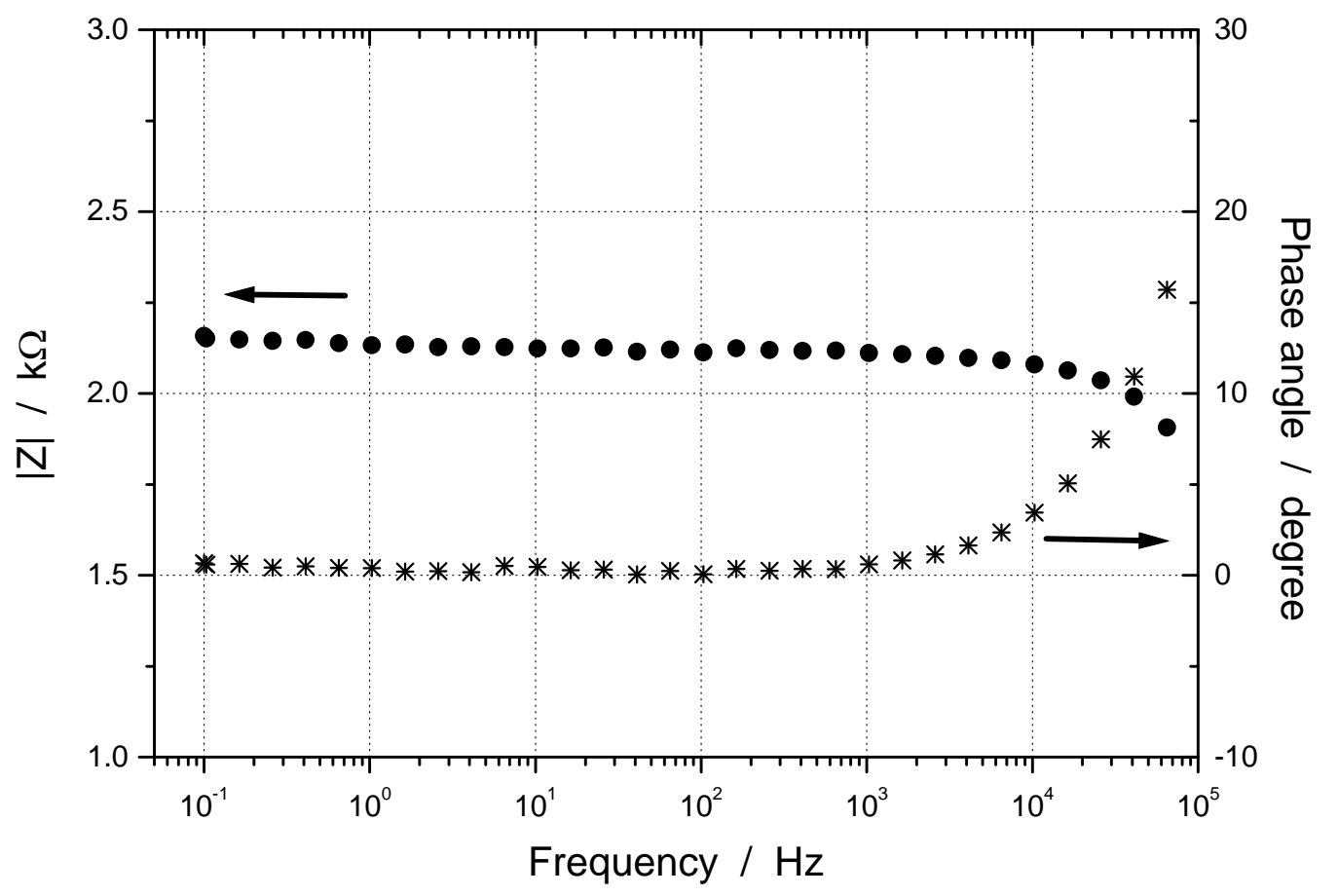

Fig. 3. Bode diagram of the impedance of a brand new saturated sulphate RE. 


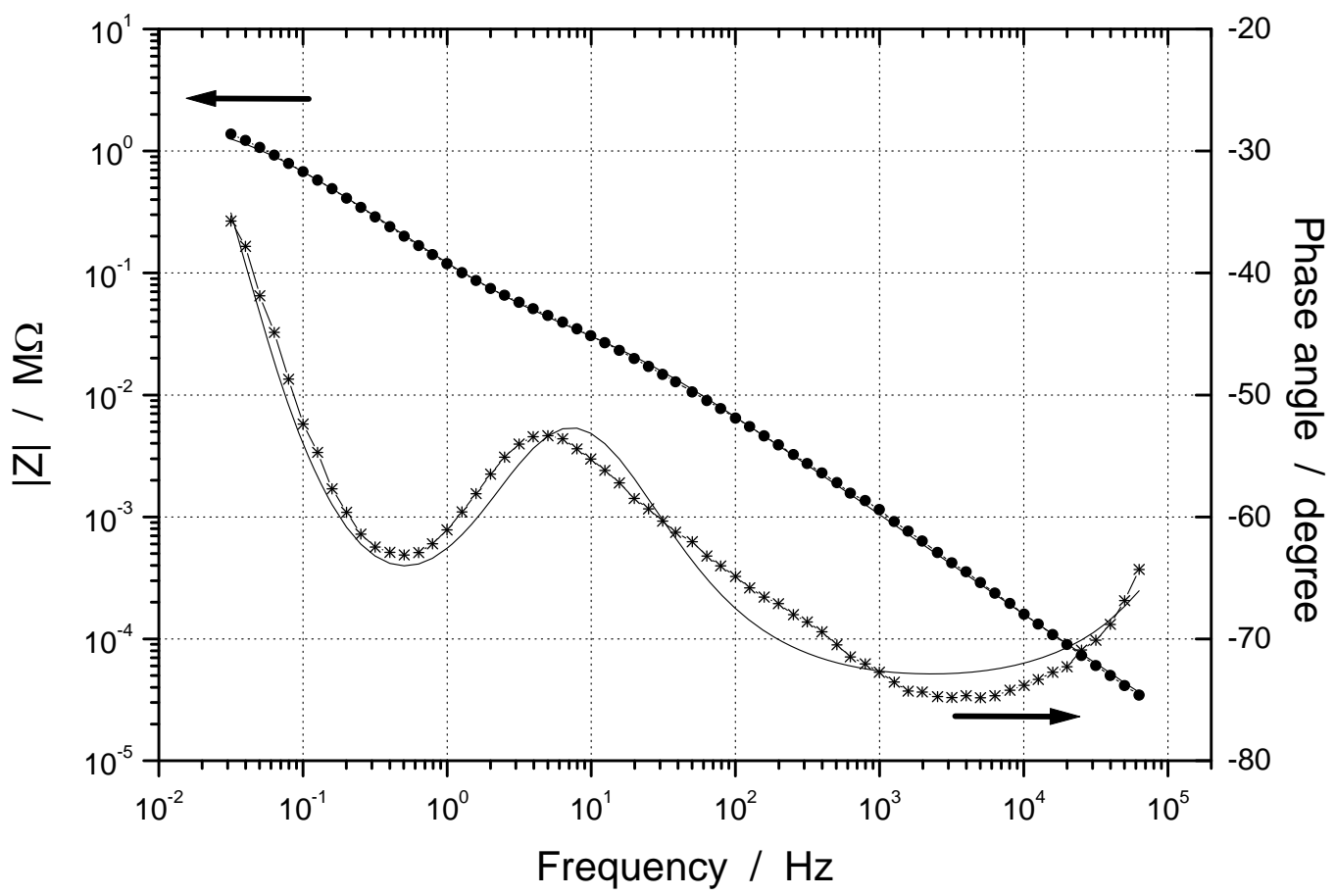

Fig. 4. Bode diagram of the measured impedance of the Pt wire $(\bullet$ modulus, $*$ phase angle). The solid lines represent the curves fitted with Eq. (13): $R_{1}=5.18 \Omega, R_{2}=23.9 \mathrm{k} \Omega, \alpha_{2}=0.813$, $Q_{2}=1.14 \mu \mathrm{F} \mathrm{s}^{\alpha_{2}-1}, R_{3}=1.87 \mathrm{M} \Omega, \alpha_{3}=0.842, Q_{3}=1.89 \mu \mathrm{F} \mathrm{s}^{\alpha_{3}-1}$. 


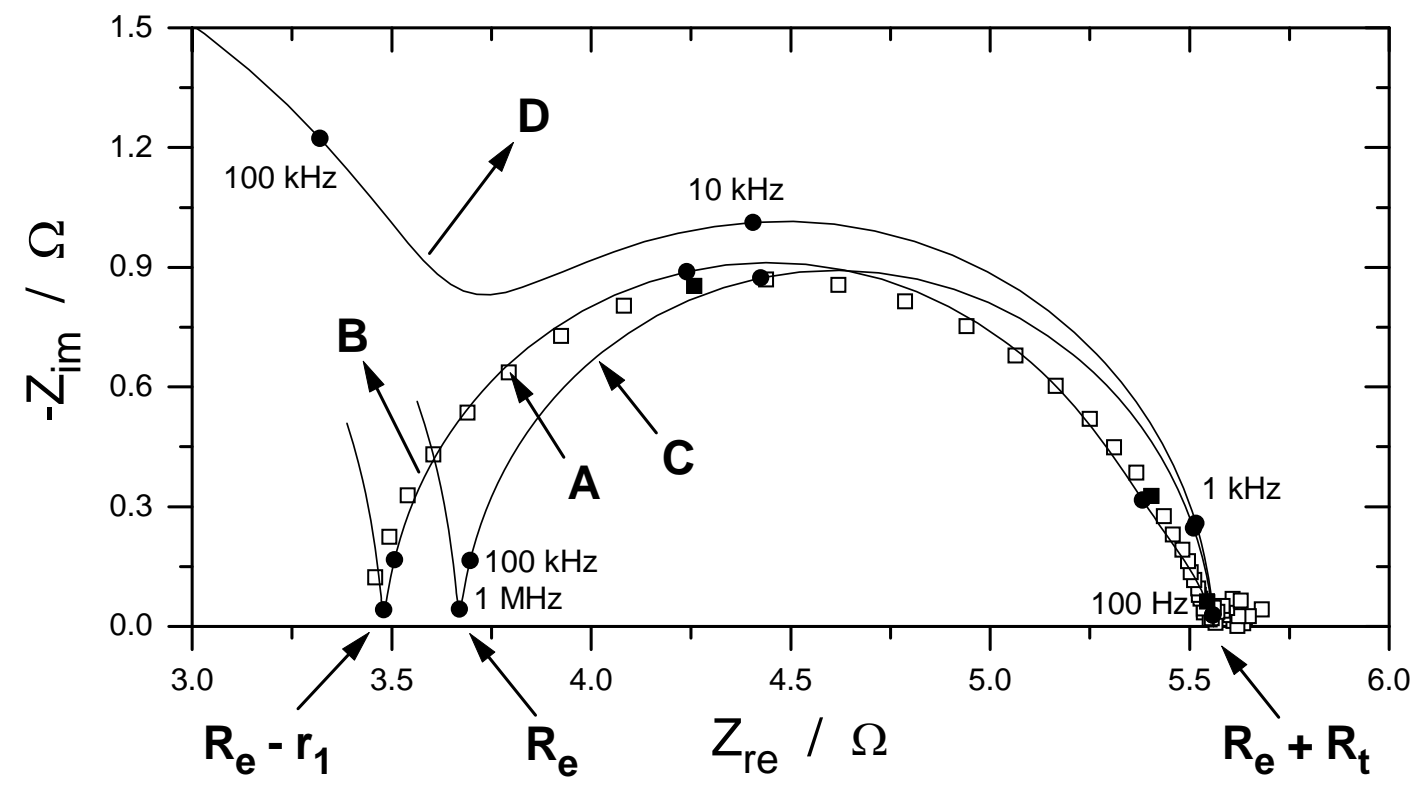

Fig. 5. EIS Nyquist diagram of $\mathrm{H}_{2}$ evolution on a Pt disk electrode in $1 \mathrm{M} \mathrm{H}_{2} \mathrm{SO}_{4}$ under current control $\left(-100 \mathrm{~mA} / \mathrm{cm}^{2}\right)$ : (A) measured with a dual RE $\left(C_{\mathrm{p}}=0.47 \mu \mathrm{F}\right)$, (B) fitted from Eq. (11) and $R_{\mathrm{e}}=3.69 \Omega, R_{\mathrm{t} 1}=1.87 \Omega, \alpha_{1}=0.969, Q_{1}=14.8 \mu \mathrm{F} \mathrm{s} \mathrm{s}^{\alpha_{1}-1}, r_{1}=0.19 \Omega$, (C) simulated with Eq. (11) with the same parameters except $r_{1}=0$, (D) simulated with Eq. (11) with the same parameters and no Pt wire $\left(C_{\mathrm{p}}=0, r_{1}=0\right)$. 


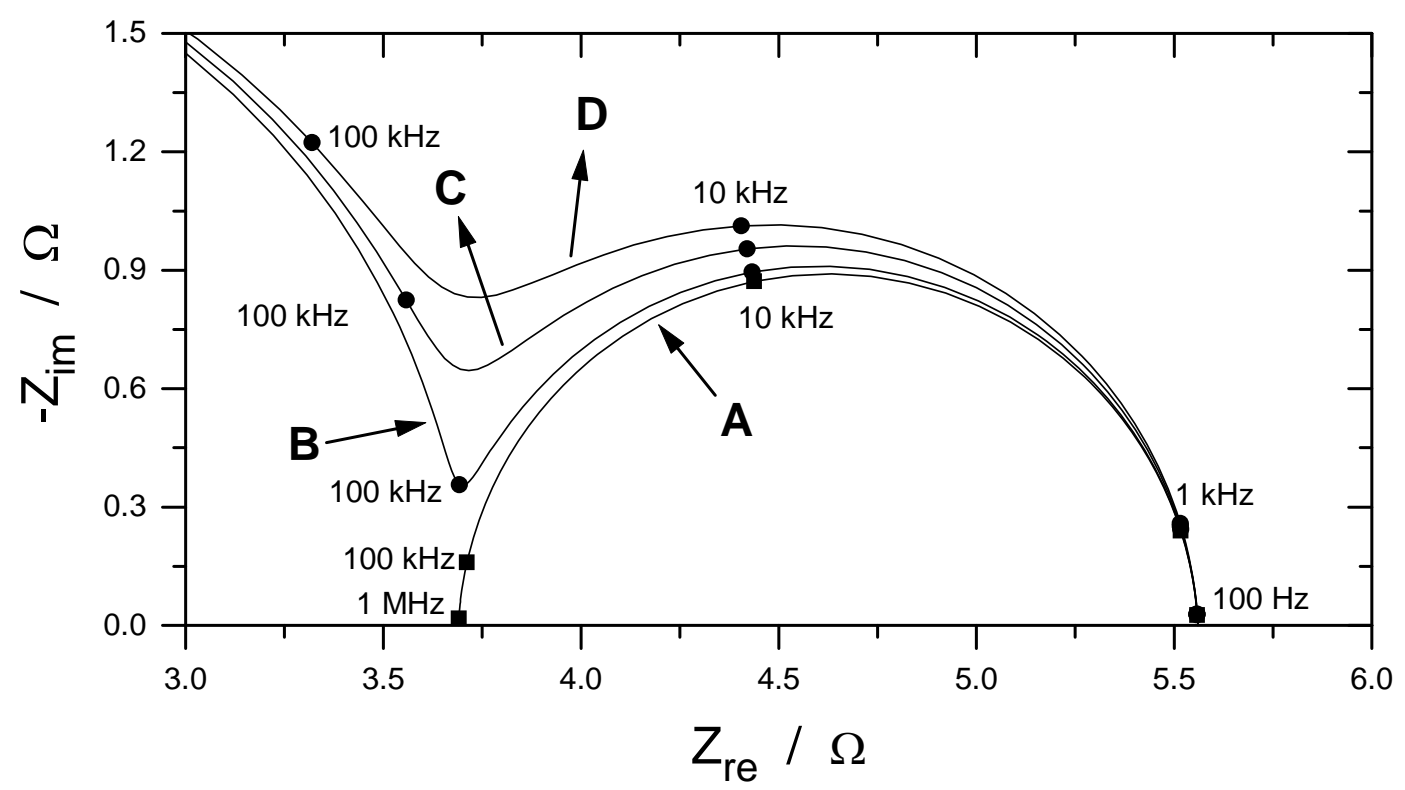

Fig. 6. Simulated EIS Nyquist diagrams for $\mathrm{H}_{2}$ evolution on a $\mathrm{Pt}$ disk electrode in $1 \mathrm{M} \mathrm{H}_{2} \mathrm{SO}_{4}$ under current control $\left(-100 \mathrm{~mA} / \mathrm{cm}^{2}\right)$ as a function of the capacitance $\mathrm{C}_{\text {in }}$ in the absence of Pt wire $\left(C_{\mathrm{p}}=0\right)$ with the same parameters as in Fig. 5 except $r_{1}=0:(\mathrm{A}) \mathrm{C}_{\text {in }}=0,(\mathrm{~B}) \mathrm{C}_{\mathrm{in}}=$ $40 \mathrm{pF},(\mathrm{C}) \mathrm{C}_{\mathrm{in}}=140 \mathrm{pF},(\mathrm{D}) \mathrm{C}_{\mathrm{in}}=240 \mathrm{pF}$. 


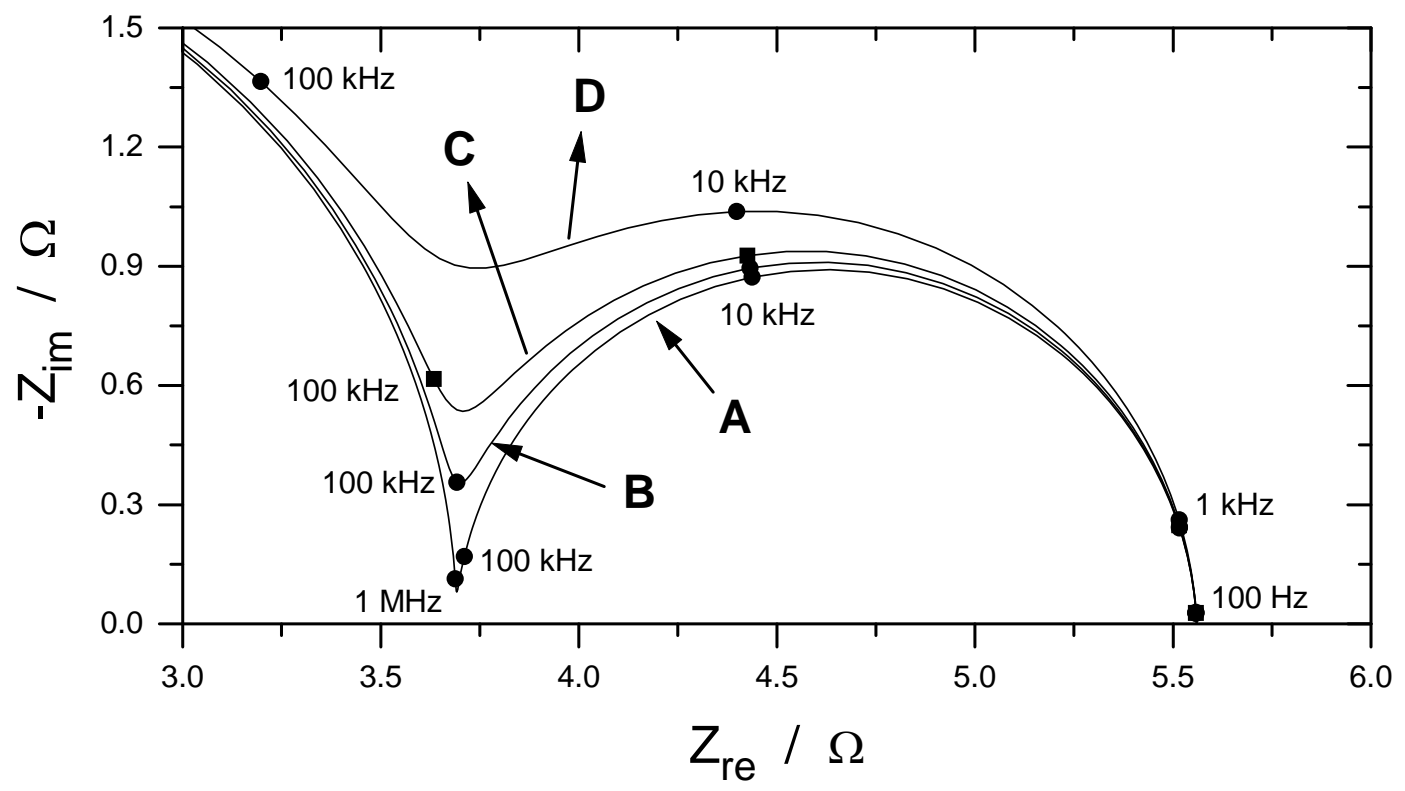

Fig. 7. Simulated EIS Nyquist diagrams for $\mathrm{H}_{2}$ evolution on a Pt disk electrode in $1 \mathrm{M} \mathrm{H}_{2} \mathrm{SO}_{4}$ under current control $\left(-100 \mathrm{~mA} / \mathrm{cm}^{2}\right)$ as a function of the resistance of the RE in the absence of Pt wire $\left(C_{\mathrm{p}}=0\right)$ with the same parameters as in Fig. 5 except $r_{1}=0$ : (A) $R_{R E}=100 \Omega$, (B) $R_{R E}=2.1 \mathrm{k} \Omega$, (C) $R_{R E}=5 \mathrm{k} \Omega$, (D) $R_{R E}=15 \mathrm{k} \Omega$. 


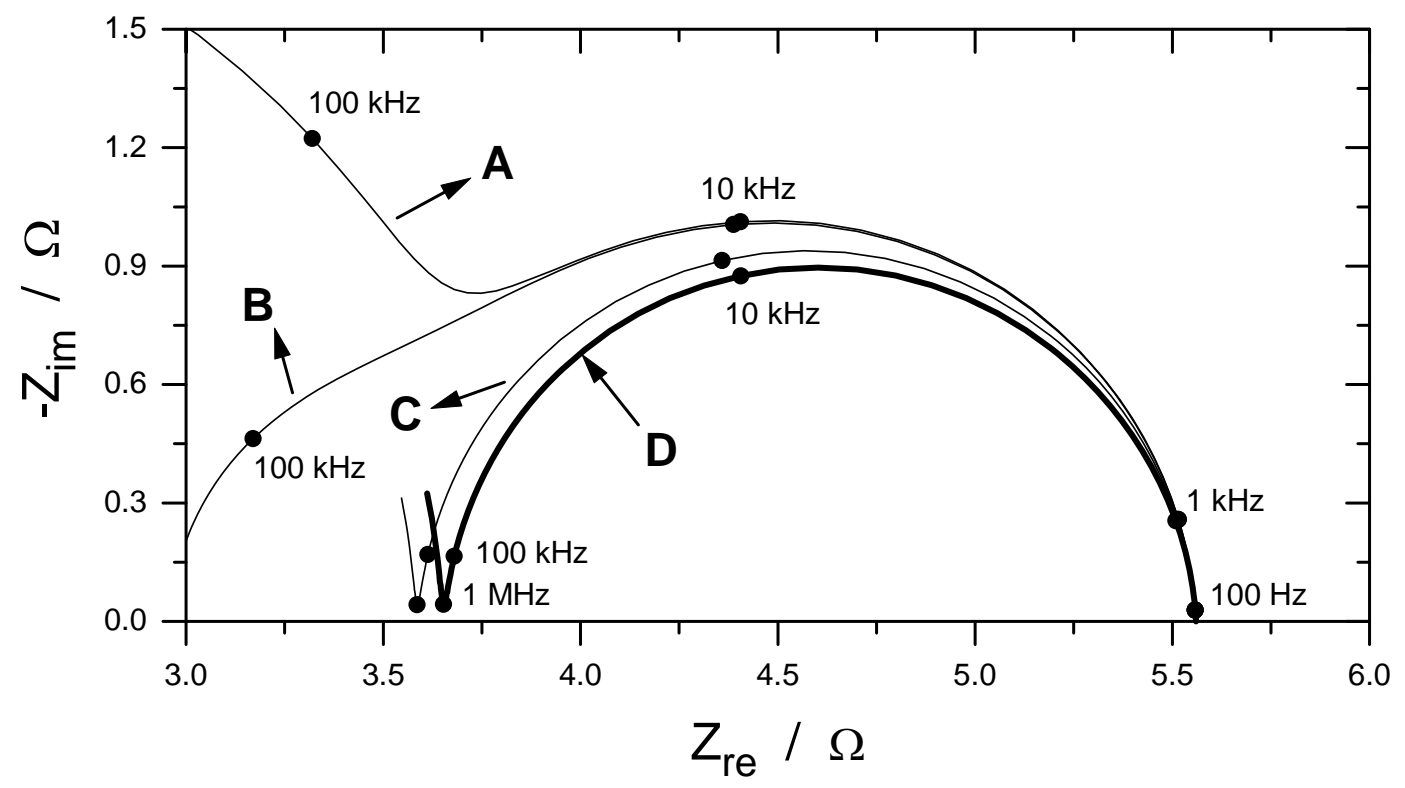

Fig. 8. Simulated EIS Nyquist diagrams for $\mathrm{H}_{2}$ evolution on a Pt disk electrode in $1 \mathrm{M} \mathrm{H}_{2} \mathrm{SO}_{4}$ under current control $\left(-100 \mathrm{~mA} / \mathrm{cm}^{2}\right)$ as a function of the capacitance $C_{p}$ with the same parameters as in Fig. 5 except $r_{1}=0$ : (A) $\mathrm{C}_{\mathrm{p}}=0$ (no Pt wire), (B) $\mathrm{C}_{\mathrm{p}}=1 \mathrm{nF}$, (C) $\mathrm{C}_{\mathrm{p}}=10 \mathrm{nF}$, (D) $\mathrm{C}_{\mathrm{p}} \geq 47 \mathrm{nF}$. 
(a)
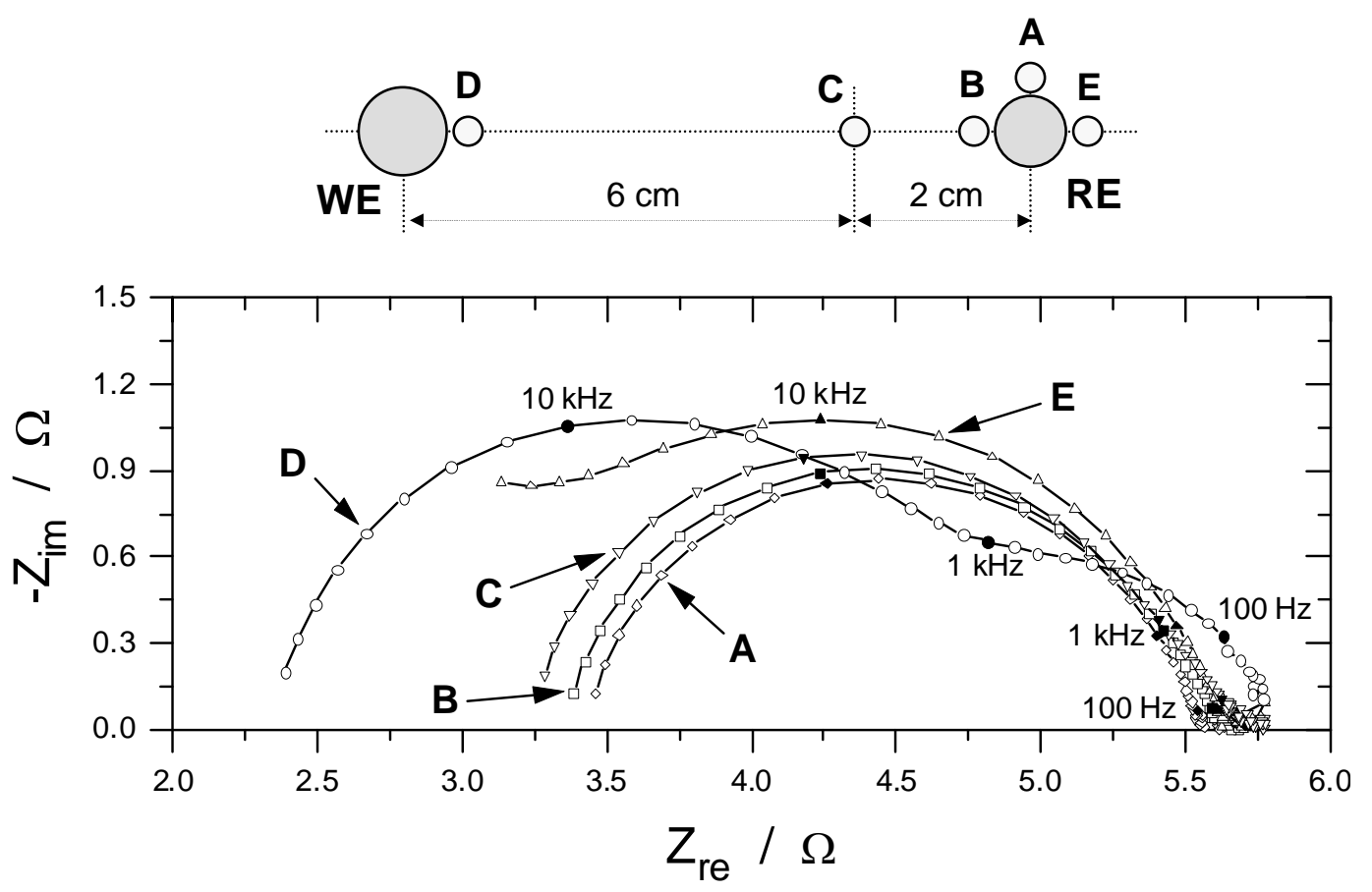

(b)

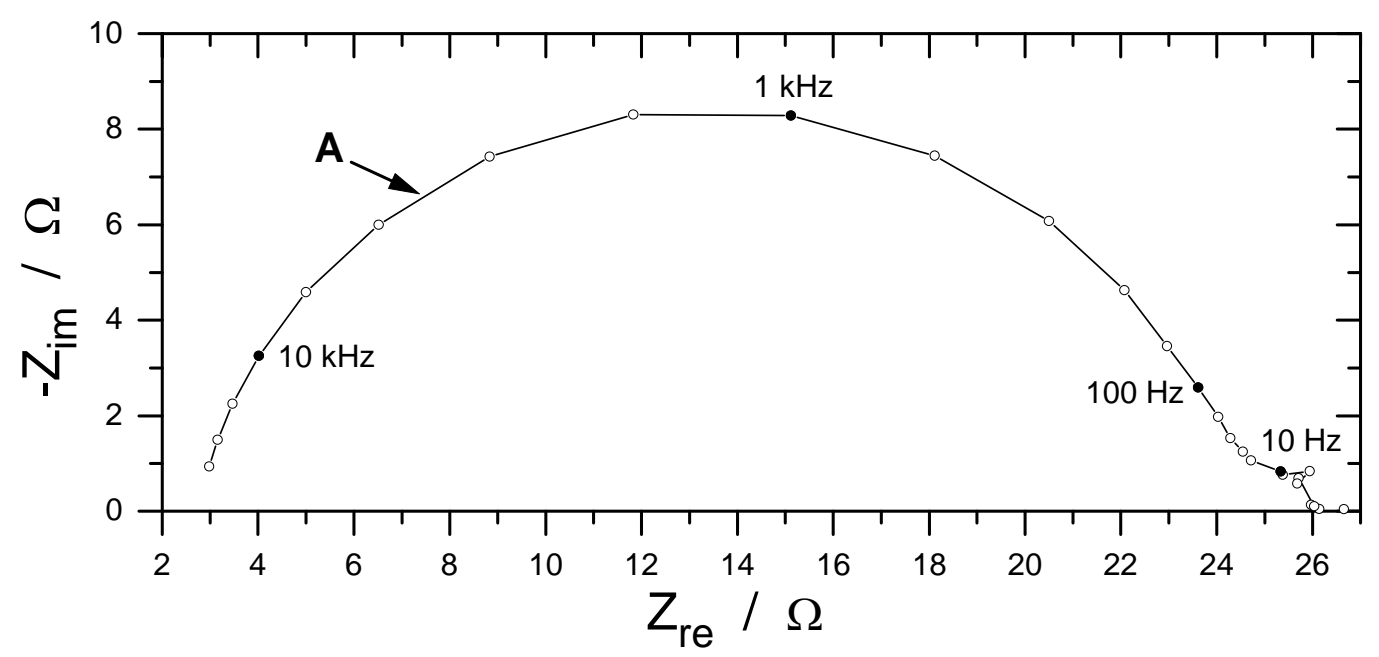

Fig. 9. EIS Nyquist diagrams measured during $\mathrm{H}_{2}$ evolution on a Pt disk WE in $1 \mathrm{M} \mathrm{H}_{2} \mathrm{SO}_{4}$ under current control with a dual $\operatorname{RE}\left(C_{\mathrm{p}}=0.47 \mu \mathrm{F}\right)$ as a function of the position of the Pt wire shown in the inset: Current density (a) $-100 \mathrm{~mA} / \mathrm{cm}^{2}$, (b) $-25 \mathrm{~mA} / \mathrm{cm}^{2}$. 


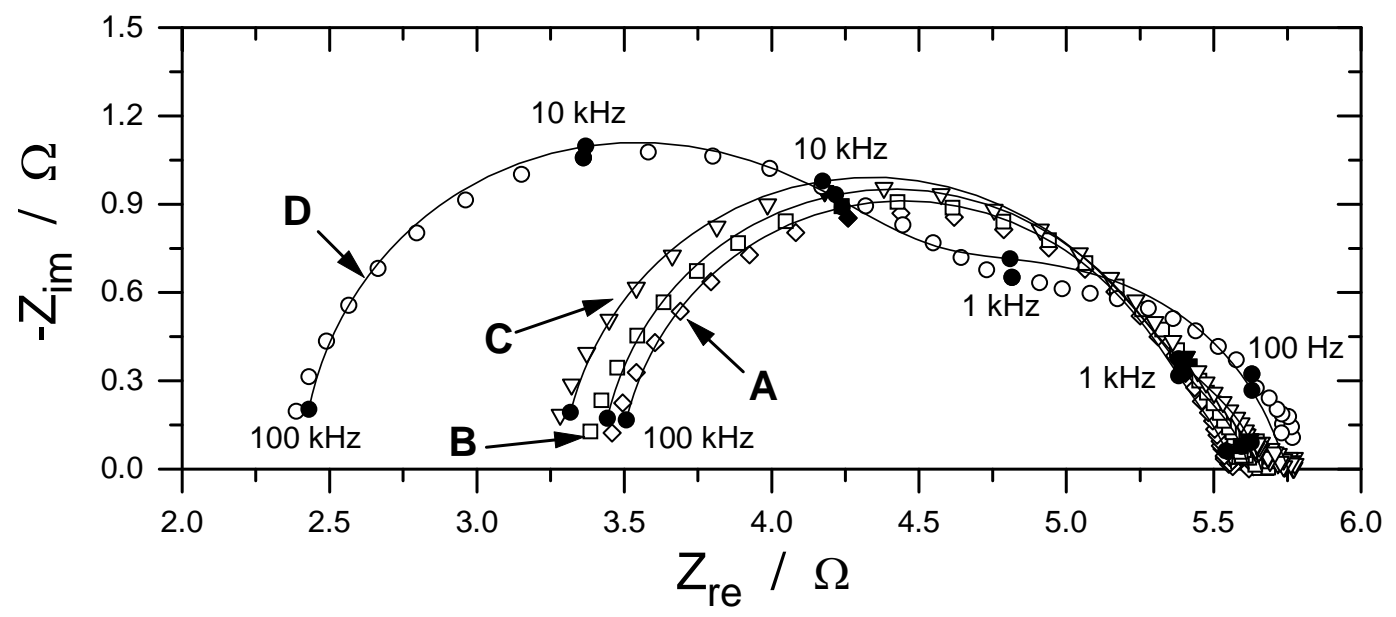

Fig. 10. Simulations of the EIS Nyquist diagrams shown in Fig. 9a (parameters of the simulation given in Table 1). 
Table 1 Parameters obtained in the fitting of the EIS diagrams shown in Fig. 9a.

\begin{tabular}{cccccc}
\hline $\begin{array}{c}\text { Position of } \\
\text { the Pt wire }\end{array}$ & $\boldsymbol{R}_{\mathbf{e}} / \boldsymbol{\Omega}$ & $\boldsymbol{R}_{\mathbf{t} 1} / \boldsymbol{\Omega}$ & $\boldsymbol{\alpha}_{\mathbf{1}}$ & $\begin{array}{c}\mathbf{Q}_{\mathbf{1}} / \\
\boldsymbol{\mu} \mathbf{F ~ s}^{\mathbf{1}^{-1}}\end{array}$ & $\boldsymbol{r}_{\mathbf{1}} / \mathbf{\Omega}$ \\
\hline & & & & & \\
A & 3.69 & 1.87 & 0.969 & 14.8 & 0.19 \\
$\mathbf{A}$ & 3.47 & 2.04 & 0.922 & 24.4 & 0 fixed \\
B & 3.71 & 1.91 & 0.978 & 12.8 & 0.27 \\
$\mathbf{C}$ & 3.65 & 2.01 & 0.969 & 12.8 & 0.35 \\
$\mathbf{D}$ & 3.78 & 1.97 & 1.000 & 8.6 & 1.36 \\
\hline
\end{tabular}

